\title{
AERODYNAMIC ANALYSIS OF A HELICOPTER FUSELAGE WITH ROTATING ROTOR HEAD
}

\author{
R. Reß, M. Grawunder, and Ch. Breitsamter \\ Institute of Aerodynamics and Fluid Mechanics \\ Technische Universität München \\ Garching 85748, Germany
}

\begin{abstract}
The present paper describes results of wind tunnel experiments obtained during a research programme aimed at drag reduction of the fuselage of a twin engine light helicopter configuration. A $1: 5$ scale model of a helicopter fuselage including a rotating rotor head and landing gear was investigated in the low-speed wind tunnel A of Technische Universität München (TUM). The modelled parts of the helicopter induce approximately $80 \%$ of the total parasite drag thus forming a major potential for shape optimizations. The present paper compares results of force and moment measurements of a baseline configuration and modified variants with an emphasis on the aerodynamic drag, lift, and yawing moment coefficients.
\end{abstract}

\section{NOMENCLATURE}

$C_{D} \quad$ Drag coefficient

$C_{L} \quad$ Lift coefficient

$C_{n} \quad$ Yawing moment coefficient (body fixed coordinate system)

$D \quad$ Drag force, $\mathrm{N}$

$L \quad$ Lift force, $\mathrm{N}$

$N \quad$ Yawing moment, $\mathrm{N} \cdot \mathrm{m}$

$S_{\text {ref }} \quad$ Reference area, $\mathrm{m}^{2}$

$l_{\text {ref }} \quad$ Reference length, $\mathrm{m}$

$p \quad$ Pressure, $\mathrm{Pa}$

$p_{\infty} \quad$ Freestream static pressure, $\mathrm{Pa}$

$U_{\infty} \quad$ Freestream velocity, $\mathrm{m} / \mathrm{s}$

$\Psi \quad$ Azimuth angle of the rotor blade in the rotor plane, deg

$\rho_{\infty} \quad$ Density of air

$\alpha \quad$ Angle of attack, deg

$\beta \quad$ Angle of sideslip, deg

This is an Open Access article distributed under the terms of the Creative Commons Attribution License 4.0, which permits unrestricted use, distribution, and reproduction in any medium, provided the original work is properly cited. 


\section{INTRODUCTION}

Saving fuel and reducing emissions is of utmost importance for future aviation. The European Commission together with the European aeronautical industry launched the CleanSky Joint Technology Initiative. Within CleanSky, environmental issues in the rotorcraft domain are addressed by the Green Rotorcraft Consortium (GRC). The GRC subproject "aerodynamic design optimization of a helicopter fuselage including a rotating rotor head" (ADHeRo) deals with the aerodynamic investigation of a helicopter fuselage of a twin engine light transport helicopter configuration with regard to reduction of parasite drag under the conditions of fast forward flight. The complete programme comprises wind tunnel tests and numerical analysis of a baseline configuration and its modified variants. It is known from earlier investigations [1] that rotor head, landing gear, and the fuselage form about $74 \%$ of the total parasite drag of a helicopter. The foreseen tasks focus on wind tunnel tests with accompanying computational fluid dynamics (CFD) analysis in order to determine appropriate shape modifications of landing gear, mast fairing, and rotor hub.

\section{WIND TUNNEL TESTING}

\subsection{Wind Tunnel Model}

The wind tunnel model (scale $1: 5$ ) consists of fuselage with mast fairing, landing gear, and a rotating rotor head including blade cuffs. The tailboom is truncated upstream the horizontal stabilizer (Fig. 1). Engine intake and outlet are closed by

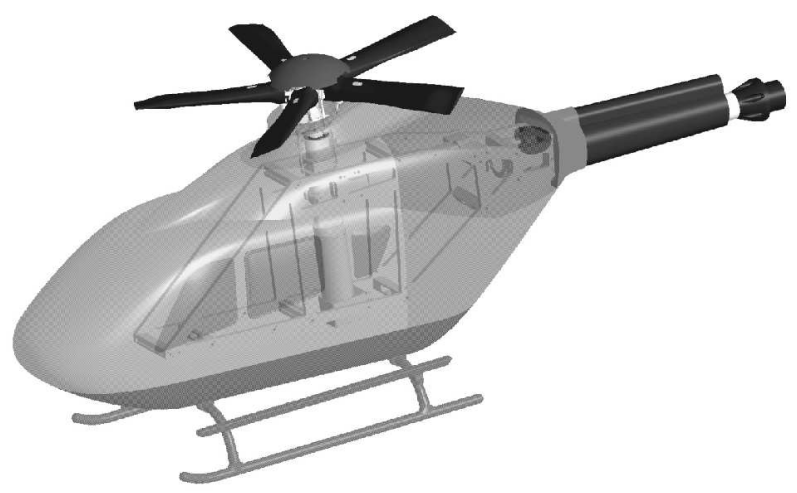

Figure 1 Modular wind tunnel model, baseline configuration 

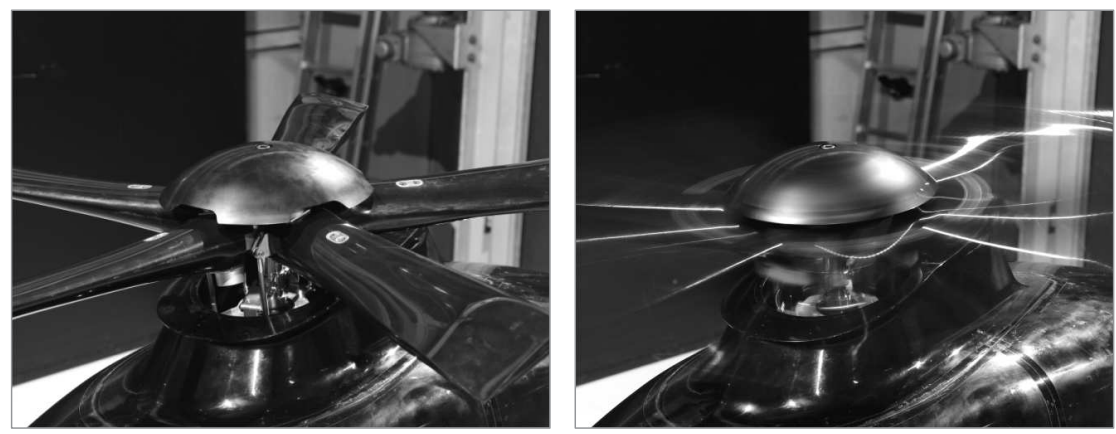

Figure 2 Five-blade rotor head
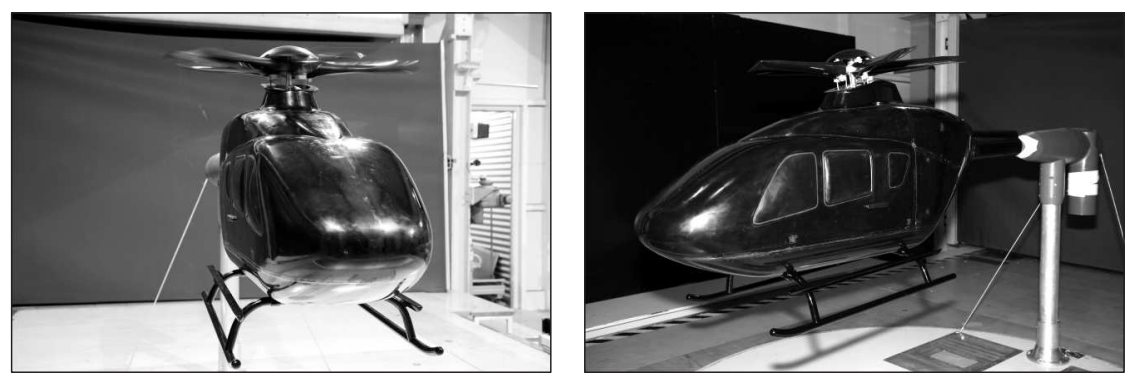

Figure 3 Model of the baseline configuration with sting mount in the test section of wind tunnel A

coverings adapted to the model geometry. The model is composed of removable and easily exchangeable components in order to facilitate quick modification and detailed drag decomposition.

The model rotor head design allows for cyclic and collective pitch adjustment (Fig. 2). Furthermore, the rotor can be locked at a fixed azimuth $(\Psi=$ const) position. The model is equipped with 218 pressure tabs for steady and unsteady surface pressure measurements, the majority of them positioned on the aft body where drag reducing efforts are expected to show effect. The model is prepared for the installation of pressure scanning systems and provision is made for using an internal balance to measure aerodynamic forces and moments acting on single components of the configuration.

For the baseline wind tunnel campaign (see $[2,3]$ ), the following modules were defined: fuselage (F0), landing gear (L0), mast fairing (M0), and rotor head (R0) including the blade cuffs. Figures 1 and 3 show the complete baseline configuration (F0M0L0R0). To separate drag originating effects, several partial 


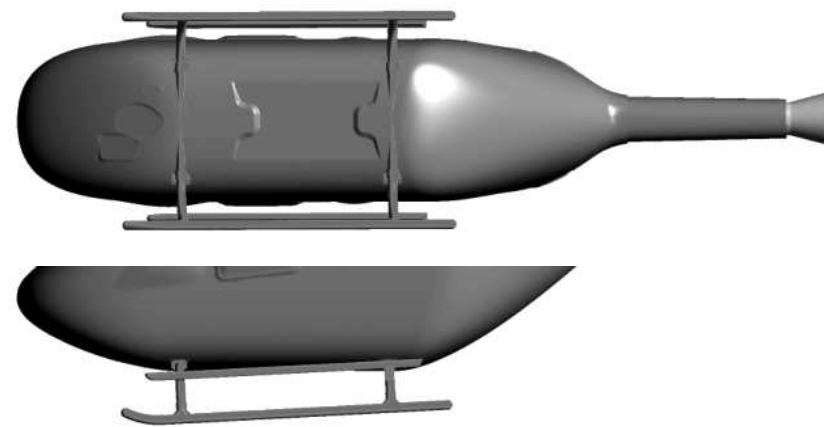

(a)
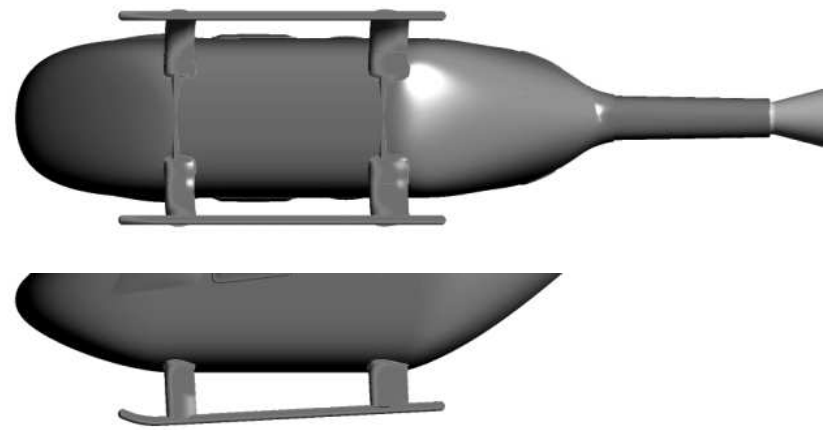

(b)
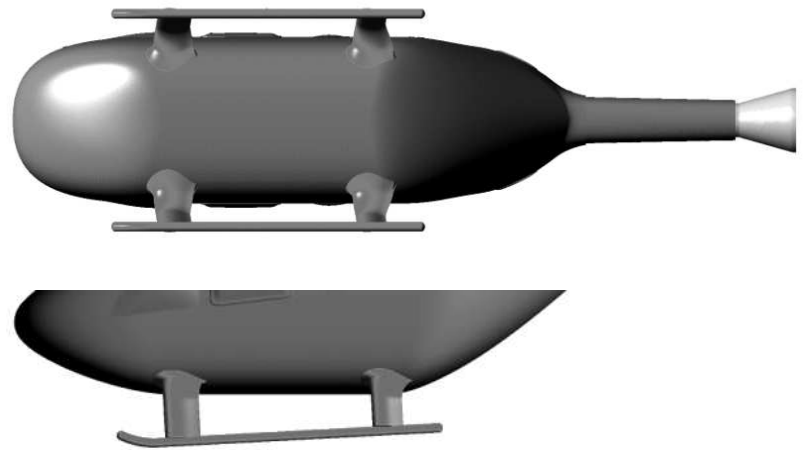

(c)

Figure 4 Baseline configurations showing fuselage F0 with landing gear L0 (a) and fuselage F1 with landing gear L1 (b) and with landing gear L2 $(c)$ 
Table 1 Configurations tested

\begin{tabular}{ll}
\hline Configuration & \multicolumn{1}{c}{ Description } \\
\hline F0M0L0 & Fuselage F0 + mast fairing M0 + landing gear L0 \\
F1M0 & Fuselage F1 + mast fairing M0 \\
F1M0L1 & Fuselage F1 + mast fairing M0 + landing gear L1 \\
F1M0L2 & Fuselage F1 + mast fairing M0 + landing gear L2 \\
F0M0R0 & Fuselage F0 + mast fairing M0 + rotor head R0 \\
F0M0L0R0 & Fuselage F0 + mast fairing M0 + landing gear L0 + rotor head R0 \\
F1M0L1R0 & Fuselage F1 + mast fairing M0 + landing gear L1 + rotor head R0 \\
F1M0L2R0 & Fuselage F1 + mast fairing M0 + landing gear L2 + rotor head R0 \\
\hline
\end{tabular}

configurations were investigated. In the second phase of ADHeRo, modified landing gear variants (L1 and L2) and a modified fuselage underbody (forming fuselage F1) were introduced. Figure 4 shows the differences between the baseline fuselage/landing gear and the two modified variants. Variants L1 and L2 feature streamlined cross tubes and modified cross tube-fuselage intersections lacking the long footstep. Mast fairing and rotor head remain unchanged (M0R0) during this phase of ADHeRo. All configurations subject to the described investigation are composed of the modules mentioned above and listed in Table 1.

During all the experiments with configurations containing R0 (i. e., rotor head fitted), the rotor head was used in the rotating mode.

For conducting the ADHeRo experimental campaign, wind tunnel A of TUM is selected. It is of low speed closed circuit (Göttingen) type and is operated with an open test section throughout ADHeRo. An underfloor six component balance is used to measure the aerodynamic forces and moments. The model

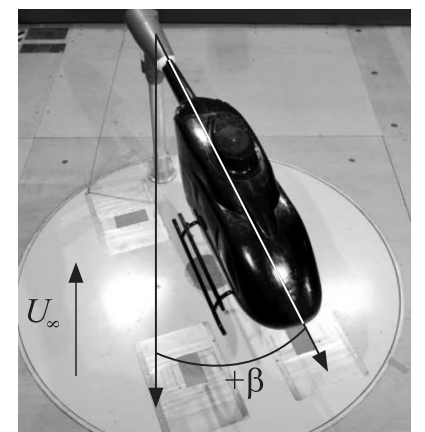

(a)

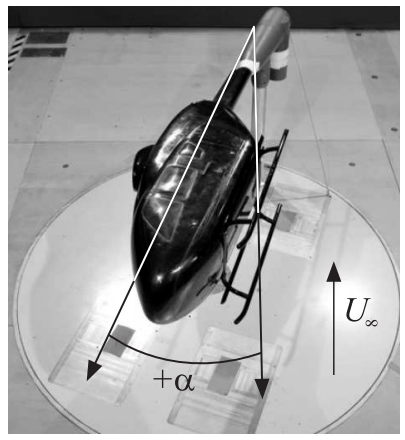

(b)

Figure 5 Adjustment of $\operatorname{AoS}(a)$ and $\operatorname{AoA}(b)$ 
is connected to the balance via the tailboom (cf. Figs. 1, 3, and 4a). A fairing around the support structure blanks out aerodynamic loads not related to the model. The experiments described in this paper were carried out at a free stream reference velocity $U_{\infty}=40 \mathrm{~m} / \mathrm{s}$ yielding a Reynolds number of about $1 \cdot 10^{6}$. The blade motion, respectively, the cyclic and collective pitch are adjusted according to the conditions of fast forward flight and are not being adapted to changes of the model's angle of attack or angle of sideslip. Viewed from above the rotor rotates counterclockwise at $963 \mathrm{rpm}$. Blade flapping and lead-lag motions are not reproduced.

The force and moment measurements are conducted at various angles of attack and angles of sideslip within a range of $-10^{\circ}$ to $+10^{\circ}$ with a step size of $2^{\circ}$ giving 25 different angles of incidence. Figure 5 shows how angle of attack (AoA) and angle of sideslip (AoS) are adjusted by means of the tailboom support and the rotatable underfloor balance in the test section of wind tunnel $\mathrm{A}$. The force and moment data are sampled and averaged over $15 \mathrm{~s}$ per measurement polar point.

\section{RESULTS}

Results are given of the force and moment measurements carried out with different fuselage configurations defined in Table 1. A focus is set on the influence of landing gear variants and the rotating rotor head on aerodynamic forces and moments. The results are presented in form of aerodynamic coefficients $C_{D}, C_{L}$, and $C_{n}$ calculated from the experimental data using the following equations:

- drag coefficient:

$$
C_{D}=\frac{D}{q_{\infty} S_{\mathrm{ref}}}
$$

- lift coefficient:

$$
C_{L}=\frac{L}{q_{\infty} S_{\mathrm{ref}}}
$$

- yawing moment coefficient:

$$
C_{n}=\frac{N}{q_{\infty} S_{\mathrm{ref}} l_{\mathrm{ref}}}
$$

- freestream dynamic pressure:

$$
q_{\infty}=\frac{1}{2} \rho_{\infty} U_{\infty}^{2}
$$

For all calculations, the same reference area and reference length were used. 


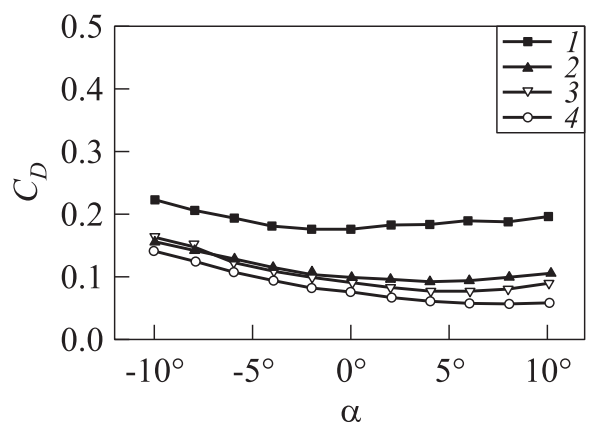

(a)

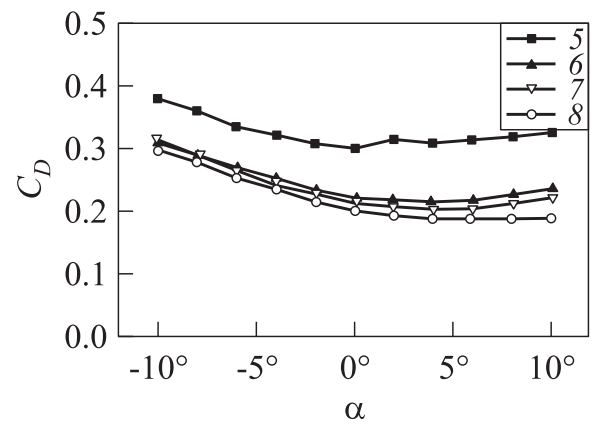

(b)

Figure 6 Drag coefficient vs. AoA, AoS $=0^{\circ}: 1-$ F0M0L0; $2-$ F1M0L1; $3-$ F1M0L2; 4 - F1M0; 5 - F0M0L0R0; 6 - F1M0L1R0; 7 - F1M0L2R0; and 8 F1M0R0

The results are plotted separately for configurations with and without rotating rotor head. The aerodynamic coefficients are presented as functions of AoA and as functions of AoS and always refer to the total drag, total lift, and total yawing moment of the configurations labelled in the legend. Figures 6 to 8 show the aerodynamic coefficients as functions of AoA at $\mathrm{AoS}=0^{\circ}$. Figure $6 a$ shows the drag coefficient as a function of AoA for configurations without rotor head thus demonstrating solely the effect of the landing gear on drag.

The curves in Fig. $6 a$ show that configurations F1M0L1 and F1M0L2 (modified landing gears) generate about $45 \%$ less drag with respect to the baseline variant F0M0L0. The F1M0L1 variant develops slightly higher drag than the F1M0L2 variant at positive AoA. Both modified variants lead to a drag level and characteristics much closer to F1M0 (fuselage and mast fairing without landing gear) than to the baseline configuration F0M0L0. From -10 to 0 degree AoA, all curves show a decreasing drag coefficient. The baseline configuration F0M0L0 has its minimum at 0 degree AoA, while the modified variants F1M0L1 and F1M0L2 show a minimum around 5 degree AoA. Configuration F1M0 without landing gear shows a further decrease of the drag coefficient towards AoA $+10^{\circ}$. Figure $6 b$ depicts the drag coefficient as a function of AoA for the configurations with rotating rotor head.

The configurations with rotating rotor generate about twice the drag compared to those without rotating rotor head. Furthermore, it is evident that the rotating rotor head has comparatively little influence on the characteristics of the drag curves. It causes a slight change of the slope of the curves in the negative range of AoA and in the range from +4 to +10 degree AoA. Apart from the fact that the projection area of the rotor disk perpendicular to the free stream changes with AoA lift and thrust generating effect of the blade cuffs must be 


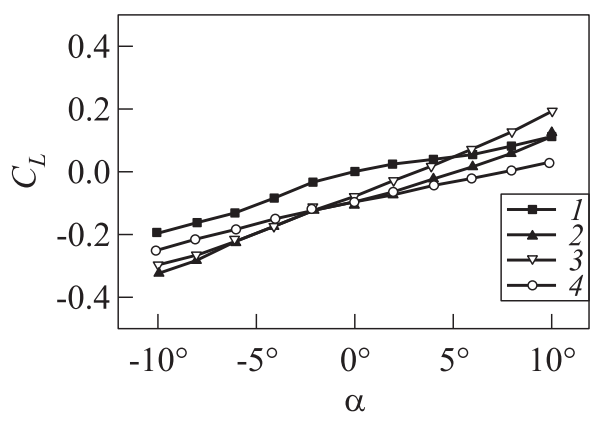

(a)

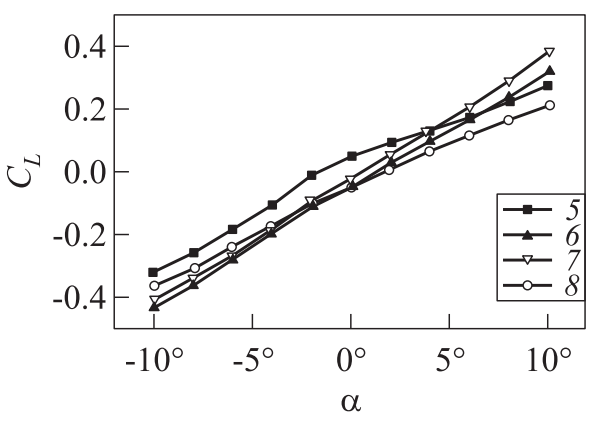

(b)

Figure 7 Lift coefficient vs. of AoA, AoS $=0^{\circ}: 1-$ F0M0L0; $2-$ F1M0L1; $3-$ F1M0L2; $4-$ F1M0; $5-$ F0M0L0R0; $6-$ F1M0L1R0; $7-$ F1M0L2R0; and $8-$ F1M0R0

taken into consideration. Figure $7 a$ depicts the lift curves as a function of AoA for the configurations without rotating rotor head.

The baseline variant (F0M0L0) generates less down force than the configuration without landing gear (F1M0) over the whole range of AoA. The curved shape of the lower aft body leads to an upward flow deflection thus generating a down force. The baseline landing gear causes a large separation region changing completely the flow pattern at the aft body (see also [3]). At negative AoA, the modified variants show a similar behavior to the baseline variant but generate significantly larger down force. In the positive range of AoA, the lift curves of the modified variants F1M0L1 and F1M0L2 show a linear behavior with the lift curve slope of the F1M0L2 variant being considerably higher (about two times) than that of the F1M0L1 configuration. It is interesting to note that the F1M0L1 variant and the baseline variant generate about the same lift at +10 degree AoA (c.f. examination of drag/lift vs. AoS below). Adding the rotating rotor head (see Fig. $7 b$ ) shows a further increase of the lift curve slopes for all configurations. The blade cuffs as well as the hub cap (see [4]) create additional lift. On the contrary, the rotating rotor creates additional down force at negative angles of attack. Furthermore, by comparing the lift curve of F0M0L0R0 and F1M0L1R0, it is obvious that the influence of the rotating rotor head changes the flow field and results in higher lift for F1M0L1R0.

In the following, the yawing moment coefficient $C_{n}$ is examined. Figure $8 a$ shows the yawing moment coefficient for the configurations without rotating rotor head and Fig. $8 b$ with rotating rotor head.

For all configurations, the yawing moment coefficient changes marginally with AoA. Both modified variants F1M0L1 and F1M0L2 (see Fig. 8a) show slightly asymmetric characteristics. A comparison of F1M0 in Fig. $8 a$ and F0M0R0 in 


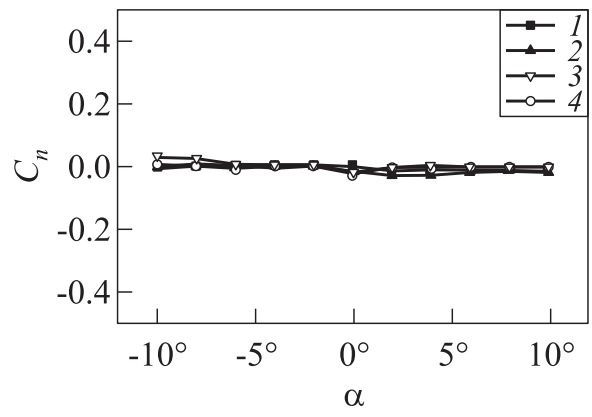

(a)

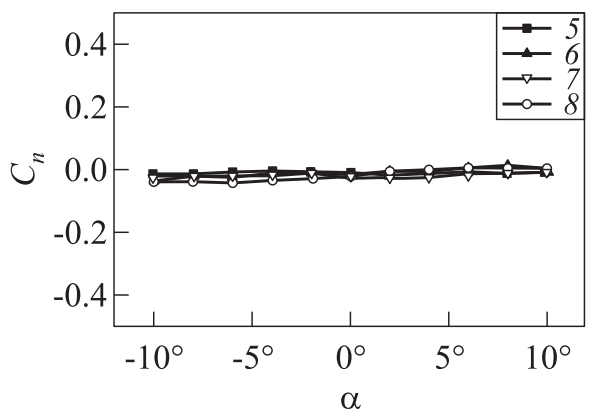

(b)

Figure 8 Yawing moment coefficient vs. AoA, AoS $=0^{\circ}: 1-$ F0M0L0; $2-$ F1M0L1; 3 - F1M0L2; 4 - F1M0; 5 - F0M0L0R0; 6 - F1M0L1R0; 7 - F1M0L2R0; and $8-$ F1M0R0

Fig. $8 b$ makes the effect of the rotating rotor head evident. At negative AoA, the rotating rotor head has more influence on the flow around the fuselage. Note that the landing gear variants dampen this effect. One also has to take into account that the experimental setup does not allow to measure the engine torque separately.

Figures 9 and 10 depict the aerodynamic coefficients with respect to the AoS at $\mathrm{AoA}=0^{\circ}$.

Figure $9 a$ depicts the drag coefficient as a function of AoS at $\mathrm{AoA}=0^{\circ}$. Variant F0M0 shows a symmetrical behavior around $\mathrm{AoA}=0^{\circ}$ which is the point of minimum projection area perpendicular to the freestream. The difference in drag between the configurations with landing gear and F1M0 increases with higher positive and negative AoA as expected with a skid landing gear possessing a smaller frontal than lateral projection area. The modified landing gear variants produce distinctively lower drag than the baseline variant. Modification F1M0L2 shows minimum drag at 0 degree AoS and slightly higher drag than configuration F1M0L1 at higher positive and negative AoS.

Figure $9 b$ shows that the influence of the rotating rotor head causes an almost constant amount of extra drag throughout the examined range of AoS (cf. Fig. $9 a$ ). Figure $9 b$ makes evident that the asymmetric flow field generated by the rotating rotor head does not show any significant effect on the characteristics of the drag curves with respect to the sideslip angle. Again, the curves for the modified landing gear resemble the behavior of the baseline variant.

In Fig. $10 a$, the lift coefficient for the fuselage and landing gear configurations is given as a function of AoS. It can be clearly seen that the helicopter fuselage configuration F1M0 generates down force at zero AoA over the whole range of AoS. In general, the configurations F0M0L0, F1M0L1, and F1MOL2 also 


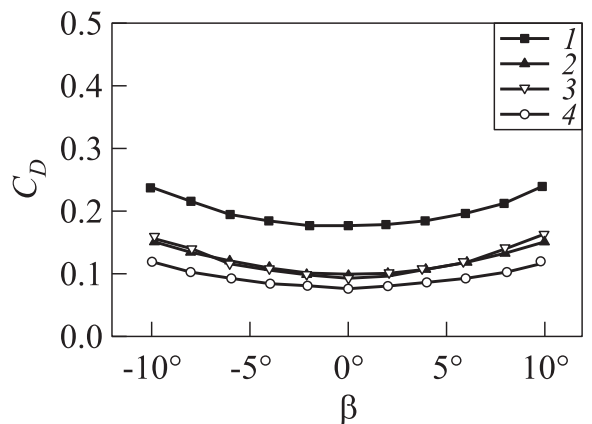

(a)

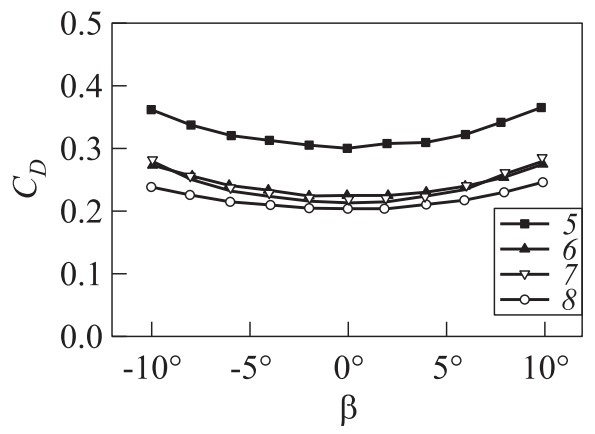

(b)

Figure 9 Drag coefficient vs. AoS, AoA $=0^{\circ}: 1-$ F0M0L0; $2-$ F1M0L1; $3-$ F1M0L2; 4 - F1M0; 5 - F0M0L0R0; 6 - F1M0L1R0; 7 - F1M0L2R0; and $8-$ F1M0R0

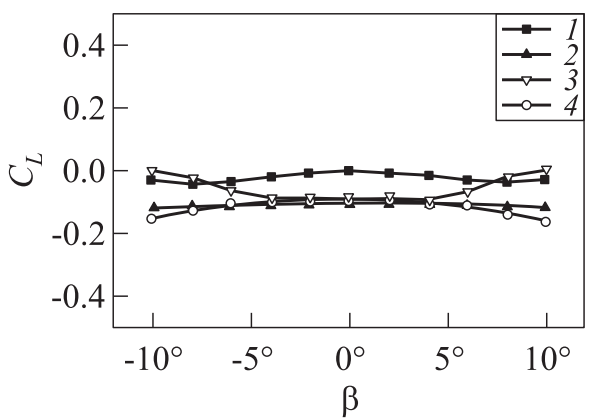

(a)

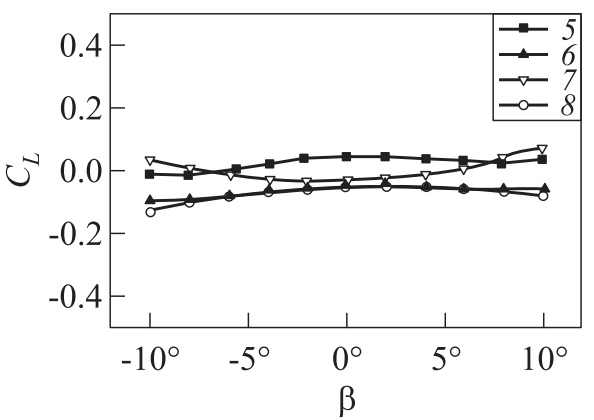

(b)

Figure 10 Lift coefficient vs. AoS, AoA $=0^{\circ}: 1-$ F0M0L0; $2-$ F1M0L1; $3-$ F1M0L2; 4 - F1M0; 5 - F0M0L0R0; 6 - F1M0L1R0; 7 - F1M0L2R0; and $8-$ F1M0R0

generate a down force over the examined range of AoS with the exception that the baseline variant F0M0L0 at 0 degree AoS and modified configuration F1M0L2 at -10 and +10 degree AoS attain lift coefficients close to zero. For the cases with modified landing gears the lift curve does not change between $\mathrm{AoS}=-4^{\circ}$ and $5^{\circ}$. In this range of AoS, the magnitude of the lift coefficient of configurations F1M0L1 and F1M0L2 is almost identical to that of F1M0. Remarkable is the difference between configurations F1M0L1 and F1M0L2. The behavior of the F1M0L1 curve closely follows that of the baseline F0M0L0 configuration with just an offset in down force. Configuration F1M0L2 decidedly reduces the down force at positive $\mathrm{AoS}>5^{\circ}$ and negative $\mathrm{AoS}<-5^{\circ}$. The fuselage-crosstube intersections obviously have a significant influence on the flow topology. 


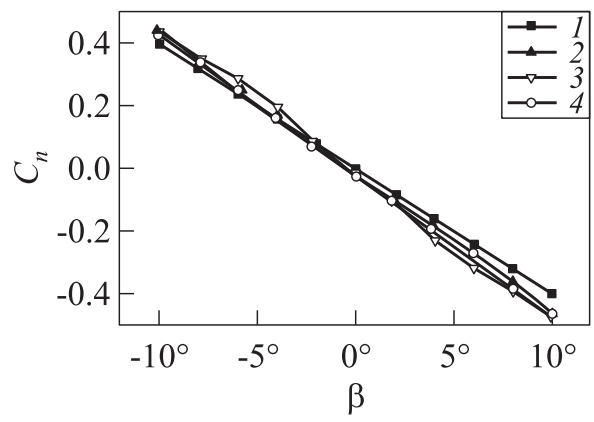

(a)

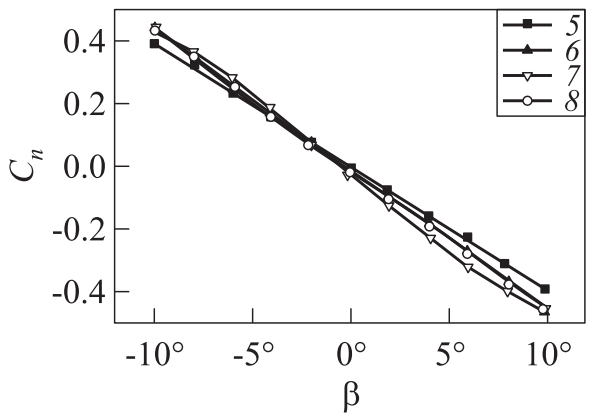

(b)

Figure 11 Yawing moment coefficient vs. AoS, AoA $=0^{\circ}: 1-$ F0M0L0; $2-$ F1M0L1; 3 - F1M0L2; 4 - F1M0; 5 - F0M0L0R0; 6 - F1M0L1R0; 7 F1M0L2R0; and $8-$ F1M0R0

Figure $10 b$ shows the lift coefficient for the fuselage, landing gear, and rotor head configurations as a function of AoS. Apparently, for all configurations, the rotating rotor head leads to an asymmetric behavior of the lift curves about AoS $=0^{\circ}$. This can be explained with the fact that cyclic pitch is not adapted to the flow conditions of flying in the direction of the AoS. The resulting velocity vector relative to the airfoil shaped parts of the blade cuffs (considering the same azimuth position) is not symmetric about the $\operatorname{AoS}=0^{\circ}$ case. For $\operatorname{AoS}>0^{\circ}$, the blade shows over the aft body an AoA lower than the incoming flow would necessitate while exhibiting over the front part of the fuselage an AoA higher than appropriate. The blade with higher AoA over the front of the fuselage is exposed to the little disturbed free stream flow conditions thus generating additional lift in the positive range of AoS. A more detailed analysis of the aerodynamic properties of the truncated blades is not available at the time.

As a main coefficient concerning the lateral stability, the yawing moment coefficient as a function of AoS is illustrated in Fig. 11. A look at Fig. 11 $a$ indicates for all tested configurations an almost linear decrease of $C_{n}$ with respect to AoS. Little differences between the configurations F1M0, F0M0L0, and F1M0L1 are evident with the latter one again following closely the F1M0 (no landing gear) configuration. Configuration F1M0L2 differs slightly from that in having a pronounced higher/lower yawing moment within the positive and negative range of 2 to 8 degree AoS.

Figure $11 b$ illustrates the influence of the rotating rotor head on the yawing moment coefficient.

It is clearly visible that at $\mathrm{AoA}=0^{\circ}$, the rotating rotor head has no significant influence on the characteristics of the yawing moment as a function of AoS. The respective yawing moment curves of Figs. $11 a$ and $11 b$ are almost identical. 


\section{CONCLUDING REMARKS AND OUTLOOK}

The present paper gives a short overview and comparison of selected force and moment data gathered within the first two phases of the GRC subproject ADHeRo. The high potential for drag reduction due to the modification of the landing gear has been demonstrated by the analysis of the data obtained by wind tunnel experiments. In general, the main cause for the parasite drag of a helicopter configuration is expected to originate from the separation region at the aft body. The investigations of the baseline campaign underline that circumstance. All the results examined in the present paper lead to the conclusion that streamlining of the cross tubes leads to flow conditions around the aft body close to those achieved with a clean underbody (no landing gear fitted or fully retracted landing gear). Especially, the tested modifications of the landing gear lead to drag coefficients $45 \%$ lower with respect to the baseline variant thus yielding a total drag close to the fuselage only configuration. The shortcoming of such a configuration is obviously an increase in down force.

The further analysis of recently acquired surface pressure and flow field data will give a detailed insight in the flow topology around the modified configurations. Furthermore, modifications of the aft body will be investigated to achieve drag reduction and at the same time, minimize down force.

\section{ACKNOWLEDGMENTS}

The research leading to these results received funding from the European Community's Seventh Framework Program (FP/2007-2013) for the Clean Sky Joint Technology Initiative under grant agreement number 270563.

The authors would like to thank the project partner Eurocopter Deutschland $\mathrm{GmbH}$ for the fruitful collaboration and valuable support.

\section{REFERENCES}

1. Wagner, S. N. 1973. Problems in estimating the drag of a helicopter. AGARD Conference Proceedings. 124.

2. Grawunder, M., R. Reß, C. Breitsamter, and N. A. Adams. 2012. Flow characteristics of a helicopter fuselage configuration including a rotating rotor head. 28th Congress (International) of the Council of the Aeronautical Sciences Proceedings. Brisbane, Australia.

3. Reß, R., M. Grawunder, C. Breitsamter, and N.A. Adams. 2012. Windkanaluntersuchung einer Hubschrauberzelle einschließlich eines rotierenden Rotorkopfes. 61. Deutscher Luft- und Raumfahrtkongress Proceedings. Berlin, Germany.

4. Vogel, F., C. Breitsamter, and N. A. Adams. 2010. Aerodynamic investigations on a helicopter main rotor hub. American Helicopter Societies 66th Annual Forum Proceedings. Phoenix, USA. 